DOI 10.37882/2500-3682.2022.01.02

\title{
ОСОБЕННОСТИ АДАПТАЦИИ КУРСАНТОВ К ОБУЧЕНИЮ В ВОЕННОМ ИНСТИТУТЕ В ЗАВИСИМОСТИ ОТ ПОКАЗАТЕЛЕЙ САМООТНОШЕНИЯ
}

\section{FEATURES OF ADAPTATION OF CADETS TO TRAINING AT A MILITARY INSTITUTE, DEPENDING ON THE INDICATORS OF SELF-ATTITUDE}

A. Kosolap

Summary: The article presents the results of a study of the correlation of the characteristics of the adaptation of cadets to the conditions of training in a military educational institution with the indicators of their self-attitude. When a person is in the process of adaptation, she realizes and perceives herself, on the one hand, as a part of society, and, on the other hand, as a unique and inimitable integrity. When a person gets into new life circumstances, conditions of existence and daily activities, he changes his idea of life and, accordingly, about himself. The study revealed the results indicating the relationship of these psychological phenomena, the more adequate the indicators of self-attitude of cadets, the more optimal the indicators of adaptation.

Keywords: socio-psychological adaptation, cadet, training conditions in a military educational institution, indicators of self-attitude.
A ктуальность. Актуальность проблемы адаптации курсантов к условиям обучения в военно-учебном заведении в наши дни приобретает всё более важное значение. Потребности практики обусловили широкий интерес учёных к исследованию этой проблематики. Существует много подходов к изучению адаптации человека к новым условиям жизни и деятельности. В настоящее время накоплен значительный материал в изучении факторов, детерминирующих процесс адаптации, критериев адаптированности личности, механизмов и динамики процесса адаптации. Мнения исследователей достаточно широко варьируются.

На наш взгляд, имеющиеся в данном направлении разработки недостаточно комплексно изучают особенности адаптационных процессов на различных уровнях. Следует отметить, что, несмотря на своеобразие различных сторон адаптации, необходимо учитывать их тесную взаимосвязь как компонентов единого адаптационного процесса. Влияние на организм факторов внешней среды приводит к изменению состояния психической сферы человека. Это приводит к перестройке нейровисцеральных и эндокринно-метаболических связей, что нередко является патологической почвой формиру-
Косолап Андрей Владимирович

Новосибирский военный ордена Жукова институт имени генерала армии И.К. Яковлева войск национальной гвардии Российской Федерации, г. Новосибирск kossolap_galina@mail.ru

Аннотация: В статье представлены результаты исследования соотношения характеристик адаптации курсантов к условиям обучения в военно-учебном заведении с показателями их самоотношения. Когда личность находится В процессе адаптации, то она осознает и воспринимает себя, с одной стороны, как часть общества, а с другой стороны, как уникальную и неповторимую целостность. Человек попадая в новые жизненные обстоятельства, условия существования и повседневной деятельности, меняет своё представление о жизни и, соответственно о самом себе. В ходе исследования выявлены результаты, свидетельствующие 0 взаимосвязи данных психологических феноменов: чем адекватнее показатели самоотношения курсантов, тем оптимальнее показатели адаптации.

Ключевые слова: социально-психологическая адаптация, курсант, условия обучения в военно-учебном заведении, показатели самоотношения.

ющихся отклонений в нервно-психическом здоровье.

При этом характер поведения человека в социальной сфере служит индикатором успешности адаптивных процессов на различных уровнях. В то же время социально-психологическая адаптация не устраняет физиологических форм приспособления, а видоизменяет и опосредует их, включая в себя как регулируемый и модифицируемый ею внутренний элемент [2].

Очень остро стоит проблема военно-профессиональной адаптации курсантов военно-учебных заведений. В последнее время в литературе и, особенно в военных источниках информации, появляется все больше публикаций, которые освещают различные аспекты этого процесса, его динамику, критерии оценки, исследуют ресурсы личности как субъекта адаптации. Особый интерес представляют концепция психической адаптации, предлагаемая В.М. Воробьевым и возможности ее использования в психологическом обеспечении учебно-воспитательного процесса. Вполне логично предположить, что военно-профессиональную адаптацию выпускников военных ВУЗов следует рассматривать как многогранный и многоэтапный процесс, который начи- 
нается с момента выбора юношей профессии офицера и подготовки к поступлению в учебное заведение по профилю конкретной военной специальности, а затем продолжается в период обучения и завершается профессиональным становлением на конкретной офицерской должности непосредственно в войсках. Каждый из этих этапов характеризуется определенными качественными и количественными изменениями организма и личности юноши на физиологическом, профессиональном и социально-психологическом уровнях. Результатом военно-профессиональной адаптации является закрепление офицерских кадров в Вооруженных силах нашей страны. В свою очередь, нарушение этого процесса на любом из этапов или уровней приведет к возникновению состояния дезадаптации крайними формами проявления которой являются нарушение состояния здоровья и изменение военно-профессиональной направленности человека [3].

Когда личность находится в процессе адаптации, то она осознает и воспринимает себя, с одной стороны, как часть общества, а, с другой стороны, как уникальную и неповторимую целостность. Человек, попадая в новые жизненные обстоятельства, условия существования и повседневной деятельности, меняет своё представление о жизни и соответственно о самом себе. Вступает в силу фактор соответствия, равновесия между человеком и внешней средой, когда человек приспосабливается к изменениям внешних и внутренних условий жизни. В этот самый момент личность должна реализовать свой адаптационный потенциал, который поможет ей совладать с окружающей жизнью. В ситуации, когда молодые люди, в связи с обучением в военном вузе изменяют обстановку своей жизнедеятельности, они встречают на своем жизненном пути некие трудности, которые им предстоит преодолеть. Решая свои проблемы самостоятельно, личность зреет, наполняет себя жизненным и профессиональным опытом, который очень важен в жизни.

Самоотношение - это эмоционально-ценностная система, которая выражает особенности отношения человека к самому себе и обеспечивает центрирование его внутреннего пространства, формирование смыслового вектора жизненного пути, активность и продуктивность жизнедеятельности. В условиях повышающихся требований к качеству подготовки профессионалов-специалистов, наибольшую значимость приобретают проблемы не только формирования у курсантов профессиональных компетенций, но и развития социально-значимых личностных качеств, таких как: самообладание, толерантность, самоуважение и в итоге самоотношение [10].

Для решения поставленных целей и задач нами были использованы следующие методы исследования:1. теоретический анализ литературы по теме исследования;2. методы сбора эмпирических данных: - наблюдение, беседа; - «Методика диагностики социально-психологической адаптации Роджерса-Даймонд» - в адаптации А.К. Осницкого; «Опросник самоотношения» разработанный В.В. Столиным и С.Р. Пантилеевым; 3. Методы качественной и количественной обработки результатов исследования. Для анализа полученных эмпирических данных применялся метод математической обработки экспериментальных данных (коэффициента ранговой корреляции Спирмена).

Исследование было реализовано на базе Новосибирского военного ордена Жукова института имени генерала армии И.К. Яковлева войск национальной гвардии Российской Федерации. В исследовании приняли участие курсанты первого курса Новосибирского военного ордена Жукова института имени генерала армии И.К. Яковлева войск национальной гвардии Российской Федерации в количестве 120 человек, в возрасте от 18 до 20 лет.

При применении метода исследования «Методика диагностики социально-психологической адаптации Роджерса-Даймонд» - в адаптации А.К. Осницкого, нами были получены следующие результаты:

Высокий показатель был выявлен по шкале «Интернальность» - 68\%. Полученный результат свидетельствует о том, что для большинства испытуемых характерен внутренний локус-контроль, т.е. они способны принимать ответственность за то, что происходит с ними, за свои поступки на себя. Они более уверены в себе, последовательны и настойчивы в достижении цели, склонны к самоанализу, общительны, спокойнее и доброжелательнее, популярнее и независимее. Поскольку такие люди в своих неудачах винят, прежде всего, себя, они испытывают больший стыд и вину, в отличие от людей, у которых доминирует внешний локус-контроль (экстернальность). Такой тип поведения сочетается с неуверенностью в своих способностях и стремлением отложить реализацию намерений на неопределенный срок, тревожностью, подозрительностью, агрессивностью. У них доминирует склонность приписывать причины происходящего внешним факторам (окружающей среде, судьбе или случаю).

Шкала «Стремление к доминированию» набрала 77\%. Из этого можно сделать вывод о том, что большинство курсантов имеют склонность к лидерству, руководству в решении задач, зачастую личностно значимые задачи решают за счет окружающих. Они обладают стремлением брать на себя инициативу в межличностных отношениях или устанавливать контроль над ними.

Следующий показатель был проанализирован по шкале «Адаптация» - 63\%. Рассматриваемый показатель 
выявляет уровень приспособления человека к существованию в обществе в соответствии с требованиями этого общества и с собственными потребностями, мотивами и интересами.

Следующая шкала - это «Эмоциональный комфорт» - 60\%. Она выявляет степень определённости в своём эмоциональном отношении к происходящей действительности, окружающим предметам и явлениям. Для респондентов, у которых эмоционального комфорт преобладает над эмоциональным дискомфортом, характерно состояние уверенности, спокойствия, удобства, когда человек всем доволен, оптимистичен, открыто выражает свои чувства, свободен от страха и тревоги.

Полученный результат по шкале «Самопринятие» характерен тем, что для 54\% опрошенных не свойственно умение и привычка относиться к себе и своим особенностям без негативной окраски, просто как к данности. Большинство испытуемых обладают самопринятием, как безоценочным, безусловно, положительным отношением к самому себе.

Проанализировав результат по шкале «Принятие других», для 41\% респондентов характерна потребность в общении, взаимодействии, совместной деятельности с другими людьми. Следующий метод исследования, который был нами применен - это «Опросник самоотношения» разработанный В.В. Столиным и С.Р. Пантилеевым.

Исходя из полученных данных, можно утверждать, что для большинства респондентов по шкале «Самоотношение» характерно глобальное самоотношение, т.е. внутренне недифференцированное чувство «за» и «против» самого себя. Данный параметр выражен и заключается в том, что представление о самом себе соответствует дружескому отношению к себе, согласию с самим собой, одобрению своих планов и желаний, эмоциональному, безусловному принятию себя таким, каков есть.

Результаты исследования по шкале «Аутосимпатия» показывают, что исследуемые имеют средний уровень самоуважения (43\%), и этот показатель не выражен. Самоуважение выступает в виде положительного мнения о самом себе, также оно эмоционально и содержательно объединяет веру в свои силы, способности, энергию, самостоятельность, оценку своих возможностей, контролировать собственную жизнь и быть самопоследовательным, понимать самого себя. У курсантов данный параметр на момент исследования развит не в полной мере, что говорит о том, что часть исследуемых не верит в свои способности и возможности, а также не имеет внутреннего понимания себя. Этот факт мы можем объяснить как раз периодом адаптации курсантов к обучению и особенностям его в военном вузе.
Кроме этого, показатель «аутосимпатия» также не выражен (23\%), что свидетельствует о том, что меньшая часть курсантов не довольна своими внешними данными и своими качественными характеристиками и иными показателями.

Анализируя результаты по шкале «Ожидаемого отношения от других, можно сделать вывод о том, что большая часть опрошенных одобряет себя в целом и в существенных частностях, доверяет себе и имеет позитивную самооценку, но 19\% исследуемых видят в себе преимущественно недостатки, владеют низкой самооценкой, готовы к самообвинению. Также, для таких курсантов свойственны такие эмоциональные реакции, как раздражение, презрение, вынесение самоприговоров.

Проанализировав данные по шкале «Самоинтерес», можно судить о том, что для 73\% респондентов характерна мера близости к самому себе, в частности интерес к собственным мыслям и чувствам, готовность общаться с собой «на равных», уверенность в своей интересности для других. Также, рассматриваемый параметр выражен и это говорит о том, что большая часть курсантов владеют направленностью на самопознание, получение информации о самом себе, склонны к постоянному изучению своего внутреннего мира, своих воспоминаний, а также к анализу собственных возможностей, личностного и субъектного потенциала.

Анализируя полученные данные по шкале «Самоуверенность» можно утверждать, что для 63\% опрошенных, свойственна уверенность в отсутствии отрицательных свойств и минусов в характере и данный показатель выражен. Однако данная черта может стать причиной многих неудач человека. Самоуверенные люди не признают личных ошибок, они свое мнение относят к единственно правильному. Нужно заметить, что рассматриваемый показатель взаимосвязан с параметром «Стремление к доминированию», который был ранее описан в методике социально-психологической адаптации Роджерса-Даймонда, который набрал 77\% среди опрошенных.

По шкале «Отношение других» было определено, что для большинства исследуемых свойственно понимание представления окружающих людей к своей персоне, а для $27 \%$ не характерен данный показатель и он не выражен.

По результатам шкалы «Самопринятие» можно судить о том, что для 61\% опрошенных, характерен данный показатель, и он ярко выражен. Это свидетельствует, что данный параметр выступает как результат самооценки индивида, определяет степень удовлетворённости личности своими характеристиками. Чем в большей степени человек принимает себя, тем выше вероятность, что он принимает других. 
При анализе шкалы «Саморуководство» было выявлено, что для большинства респондентов важную роль играет последовательность в реализации личных планов в собственной жизни, собственная предсказуемость, а также настроенность на определенный жизненный ритм и достижение значимых целей. Во внимание стоит взять тот момент, что для 39\% исследуемых не характерен данный показатель, он не выражен. Это означает, что часть курсантов не настроена на формирование и реализацию своих идей.

Анализируя результаты исследования по шкале «Самообвинение», можно сделать вывод о том, что $35 \%$ опрошенных не свойственен такой критерий, как самообвинение, он не выражен. Такие курсанты характеризуются тем, что, когда они совершают ошибки, они стараются вытеснить неприятные переживания. Для этого они находят интересующую их деятельность и таким образом, они отвлекаются и получают положительные эмоции. Но, для курсантов, которых характерен данный показатель, самообвинение является признанием собственных ошибок, а совершенные ими ошибки могут быть как истинными, так и ложными.

Рассматривая результат по шкале «Самоинтерес» можно говорить о том, что большинство курсантов - 75\% заинтересованы в том, чтобы развиваться и становиться лучше. Данный параметр ярко выражен. Для таких курсантов свойственен интерес к собственным мыслям и чувствам, готовность общаться с собой и уверенность в своей интересности для других.

Проанализировав полученные результаты по шкале «Самопонимание» мы можем говорить о том, что для $60 \%$ респондентов характерен данный критерий, он выражен. Это значит, что большинство курсантов дают себе оценку более точно, у них развит процесс саморефлексии.

На втором этапе нашего исследования, для вы- явления взаимосвязи исследуемых переменных был проведен корреляционный анализ с использованием коэффициента ранговой корреляции Спирмена. В результате были получены взаимосвязи между шкалами «Общий индекс соиально-психологической адаптации» положительно коррелирует со шкалой «Общий индекс самоотношения» $\left(0,71\right.$ при $\left.r^{*} \geq 0,5\right)$, что свидетельствует о взаимосвязи данных психологических феноменов, чем адекватнее показатели самоотношения курсантов, тем оптимальнее показатели адаптации.

Вывод. Таким образом, военно-профессиональная адаптация курсантов военно-учебных заведений представляет собой сложный комплекс мероприятий направленных на формирование у молодых людей профессионально важных качеств определяющих успешность самостоятельной деятельности офицера определенной специальности. Основными моментами этого процесса являются: приобретение и развитие устойчивого интереса к профессии кадрового военнослужащего, совершенствование физиологических механизмов приспособления к условиям военной службы, накопление теоретических знаний, практических навыков, умений и опыта работы по конкретной военной специальности, налаживание деловых и личных контактов с воинским коллективом.

Прогнозирование успешности военно-профессиональной адаптации выпускников военно-учебных заведений, управление этим процессом - это комплексная задача специалистов различного профиля, осуществление которой возможно только при наличии приемственности и гибкой обратной связи в системе «военный комиссариат - военно-учебное заведение - воинская часть». Главным звеном и координирующим центром в этой цепочке является военно-учебное заведение, а период обучения будущего офицера - основным этапом рассматриваемого процесса. Поэтому проблема адаптации курсантов военно-учебного заведения является особенно важной.

\section{ЛИТЕРАТУРА}

1. Буховцева, 0.В. Оптимизации процесса адаптации студентов 1 курса / О.В. Буховцева // Известия РГПУ им. А.И. Герцена. - 2011. - № 132. - С. 242-248.

2. Волковская, Т.Н. Современные теоретико-методологические подходы к пониманию феномена адаптации / Т.Н. Волковская, Т.М. Марченко // Проблемы современного педагогического образования. - 2018. - № 61-4. - С. 269-272.

3. Герасимов, П.Е. Теоретические аспекты проблемы «Самоотношения» / П.Е. Герасимов // Ученые записки пед. ин-та им. Н.Г. Чернышевского. Сер.: Психология. Педагогика. -2010 . - № 4. - С. 60-84.

4. Дахина, Т.В. Генезис понятия «Адаптация» в психологии / Т.В. Дахина // Вестник Астраханского государственного технического университета. - 2007. № 5 (40). - С. 175-179.

5. Диагностика социально-психологической адаптации (К. Роджерс, Р. Даймонд) / Фетискин Н. П., Козлов В.В., Мануйлов Г. М. // Социально-психологическая диагностика развития личности и малых групп. - М., Изд-во Института Психотерапии, 2002. - С. 193-197.

6. Жигулин, А.А. Трансформация параметров самоотношения студентов-юристов на различных этапах обучения в вузе / А.А. Жигулин, В.Н. Кручинин // Научно-исследовательские публикации. - 2018. - № 4. - С. 99-104. 
7. Осницкий, А.К. Определение характеристик социальной адаптации / А.К. Осницкий // Психология и школа. - 2004. - № 1. - С. 43-56.

8. Панькова, А.А. Особенности самоотношения и копинг-стратегий в юношеском возрасте (к постановке проблемы) / А.А. Панькова // Вестн. Пермского гос. гум.-пед. ун-та. Сер.: Психологические и педагогические науки. - 2020. - № 1. - С. 114-119.

9. Пашкин, С.Б. Психологическое благополучие как условие успешной адаптации курсантов к повседневной деятельности / С.Б. Пашкин, А.В. Головачёв, А.С. Савинская // Военный инженер. - 2020. - № 1 (15). - С. 43-54.

10. Столин, В.В. Самосознание личности / В.В. Столин. - М.: Изд-во Моск. ун-та, 1983. - 284 с.

(c Косолап Андрей Владимирович (kossolap_galina@mail.ru).

Журнал «Современная наука: актуальные проблемы теории и практики»

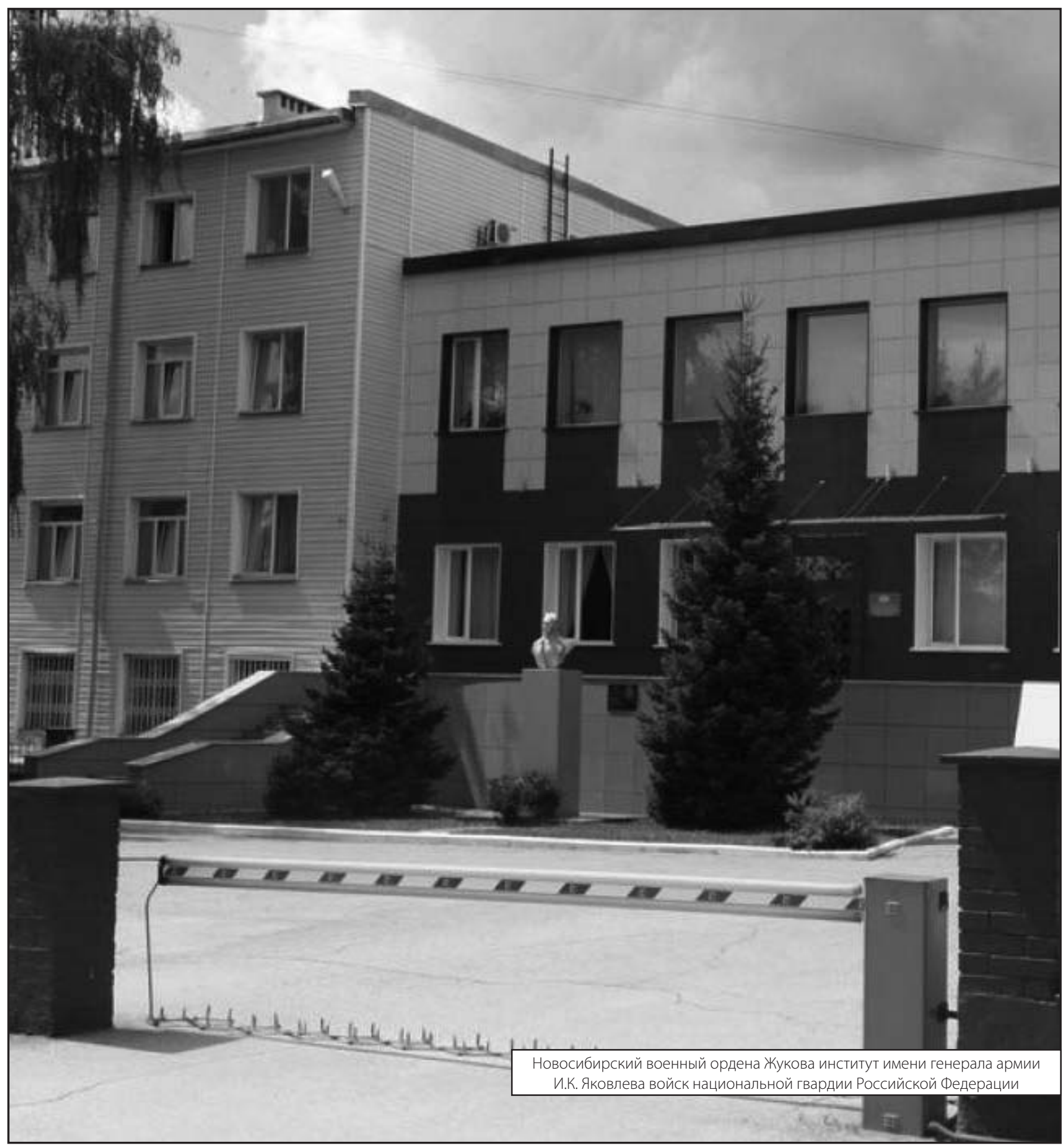

